\title{
Bubble Departure Diameter and Bubble Release Frequency Measurement from TAMU Subcooled Flow Boiling Experiment
}

\author{
Junsoo Yoo
}

December 2016

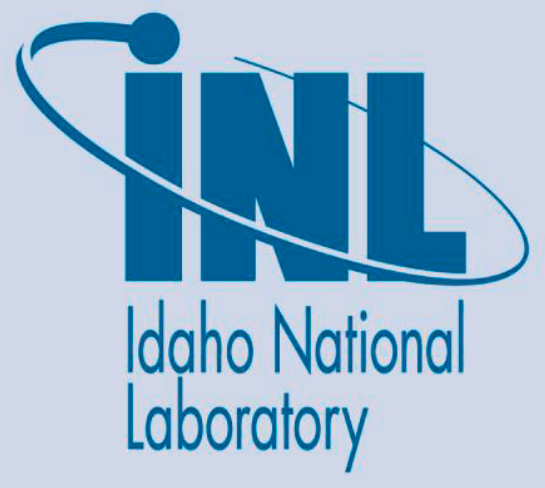

The INL is a U.S. Department of Energy National Laboratory operated by Battelle Energy Alliance 


\section{DISCLAIMER}

This information was prepared as an account of work sponsored by an agency of the U.S. Government. Neither the U.S. Government nor any agency thereof, nor any of their employees, makes any warranty, expressed or implied, or assumes any legal liability or responsibility for the accuracy, completeness, or usefulness, of any information, apparatus, product, or process disclosed, or represents that its use would not infringe privately owned rights. References herein to any specific commercial product, process, or service by trade name, trade mark, manufacturer, or otherwise, does not necessarily constitute or imply its endorsement, recommendation, or favoring by the U.S. Government or any agency thereof. The views and opinions of authors expressed herein do not necessarily state or reflect those of the U.S. Government or any agency thereof. 


\title{
Bubble Departure Diameter and Bubble Release Frequency Measurement from TAMU Subcooled Flow Boiling Experiment
}

\author{
Junsoo Yoo
}

December 2016

Idaho National Laboratory Idaho Falls, Idaho 83415

http://www.inl.gov

Prepared for the

U.S. Department of Energy

Office of Nuclear Energy

Under DOE Idaho Operations Office

Contract DE-AC05-00OR22725 


\begin{abstract}
The bubble departure diameter and bubble release frequency were obtained through the analysis of TAMU subcooled flow boiling experimental data. The numerous images of bubbles at departure were analyzed for each experimental condition to achieve the reliable statistics of the measured bubble parameters. The results are provided in this report with simple discussion.
\end{abstract}




\section{CONTENTS}

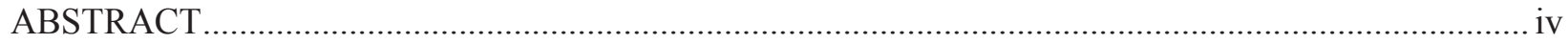

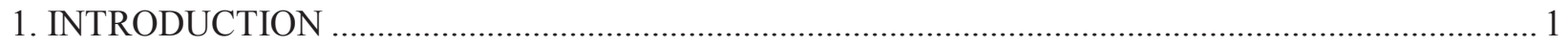

2. TEST BOUNDARY CONDITIONS AND RESULTS ............................................................... 1

2.1. TAMU subcooled flow boiling experiment and test conditions ....................................... 1

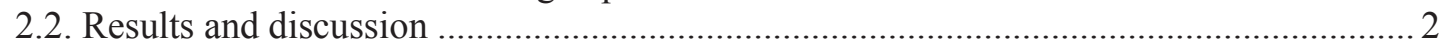

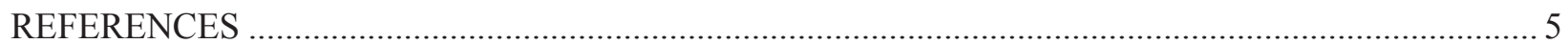




\section{FIGURES}

Figure 1. Cameras arrangement around the transparent test section for TAMU subcooled flow boiling experiment $[1,3]$

Figure 2. A typical growth behavior of sliding bubble after departure from a single nucleation site

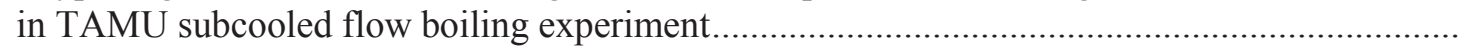

Figure 3. Comparison of measured bubble departure diameter with model predictions 


\section{Bubble Departure Diameter and Bubble Release Frequency Measurement from TAMU Subcooled Flow Boiling Experiment}

\section{INTRODUCTION}

The TAMU subcooled flow boiling experimental data was analyzed for the purpose of achieving information for the bubble departure diameter and bubble release frequency. The boiling bubble images taken under 16 different subcooled flow boiling conditions were analyzed and the results are provided in this report. Since the bubble release frequency was already reported through the previous documents [1, 2], the following discussion is focused on the bubble departure diameter.

\section{TEST BOUNDARY CONDITIONS AND RESULTS}

\subsection{TAMU subcooled flow boiling experiment and test conditions}

The detailed description of TAMU subcooled flow boiling experiment is given in Yoo et al. $[1,3]$. This section describes only the main features of the experiment. The TAMU subcooled flow boiling experiment was performed in a vertical square test channel and a heater wall was placed on one side of the test section to create the boiling (total heated length $\mathrm{L}_{0}=224 \mathrm{~mm}$, see Figure 1). The working fluid was refrigerant NOVEC 7000 (3M, Inc.). During the whole process of experiment only a single active nucleation site was maintained to facilitate the observation of boiling bubbles through visualization. Three high speed cameras and one infrared (IR) camera were used as shown in Figure 1 to observe the bubble characteristics and associated wall heat transfer, respectively. The experiment was performed at 16 different test conditions, and bubbles were typically observed to slide along the heated surface after departing from a single nucleation site within these conditions. 


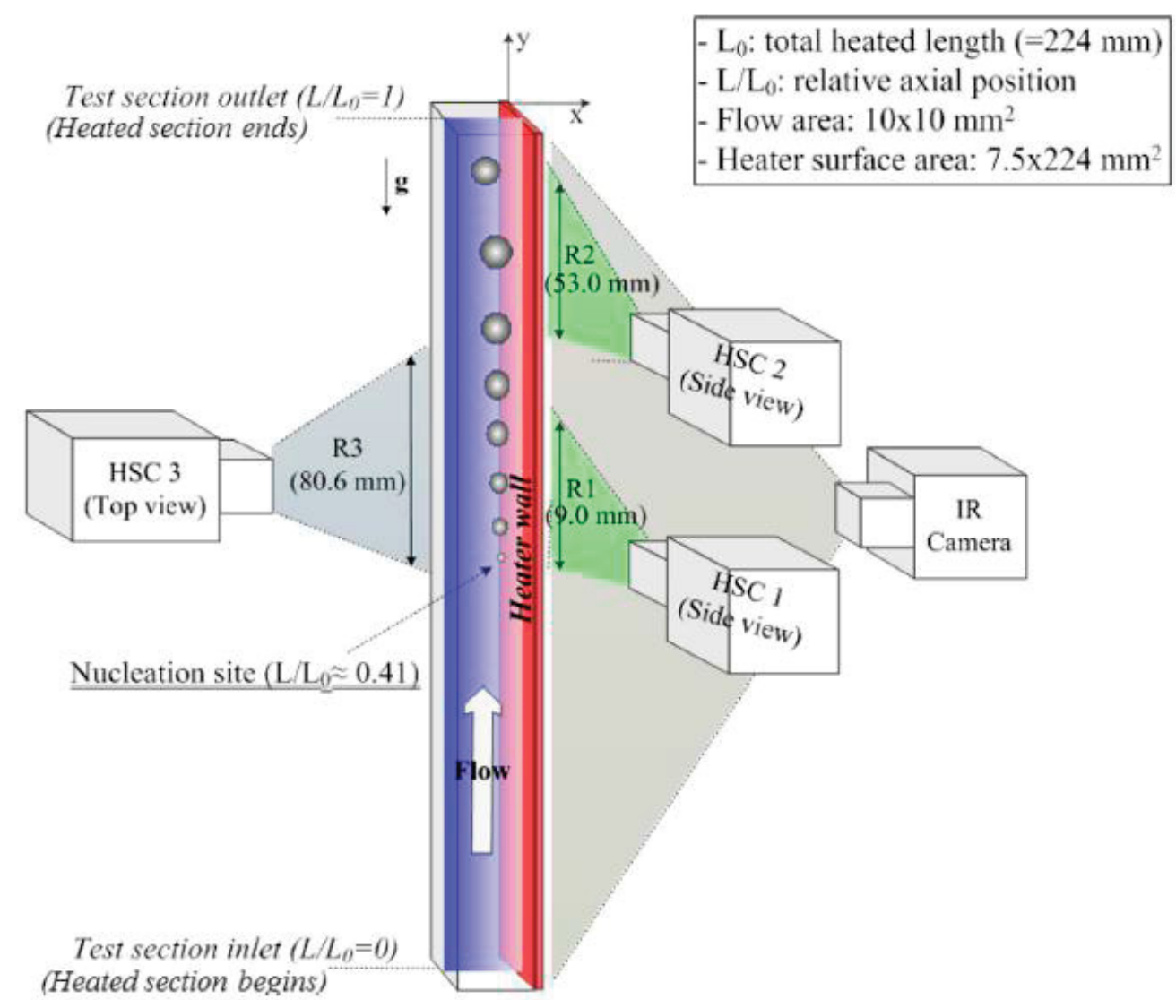

Figure 1. Cameras arrangement around the transparent test section for TAMU subcooled flow boiling experiment $[1,3]$

\subsection{Results and discussion}

The main issue of measuring the bubble departure diameter from the TAMU subcooled flow boiling experiment is that it is difficult to define the exact moment of bubble departure at the nucleation site. This is mainly because the boiling bubbles interacted vigorously at the nucleation site and the bubbles typically showed bouncing motion (i.e., detaching from the wall and reattaching to the wall) before they left the nucleation site through sliding. The effect of bouncing motion on the bubble growth behavior is shown as bouncing peak in Figure 2 (the axial location of sliding bubbles is represented as $\mathrm{L} / \mathrm{L}_{0}$; $\mathrm{L}$ is the relative axial location within the total heated length $\mathrm{L}_{0}$ ). In order to overcome the difficulties of measuring the bubble size at departure, we measured the bubble diameter at the moment when the bubbles began to slide and considered it as bubble departure diameter (the bubble release frequency was measured similarly [1]).

The test boundary conditions and measured values of bubble release frequency $\left(f_{b, 0}\right)$ and bubble departure diameter $\left(D_{d}\right)$ are summarized in Table 1. About 300-500 departure bubbles were analyzed to obtain the average diameter at departure and bubble release frequency. The uncertainty of the bubble size measurement was estimated $\pm 17.5 \mu \mathrm{m}[3]$.

The experimental results for the bubble departure diameter were compared with the model predictions. The results are shown in Figure 3. A total of four models were used for this comparison: Unal [4], Basu et al. [5], Prodanovic et al. [6], and Thorncroft [7]. The static angle, which was not measured from the experiment but required as model input, was taken as $45^{\circ}$ or $20^{\circ}$ while applying Basu et al. [5] and 
Thorncroft et al. [7]'s model. The model predictions with Basu et al. [5] and Thorncroft et al. [7] showed good agreement with the experimental data while the model predictions with Unal [4] and Prodanovic et al. [6] significantly underestimated the measurements. It is considered that the discrepancy mainly arises from the empiricism in the model predictions. Also, the performance of the individual component models used in the force balance model of Thorncroft et al. [7] (e.g., bubble growth model, drag force model) needs more investigation.

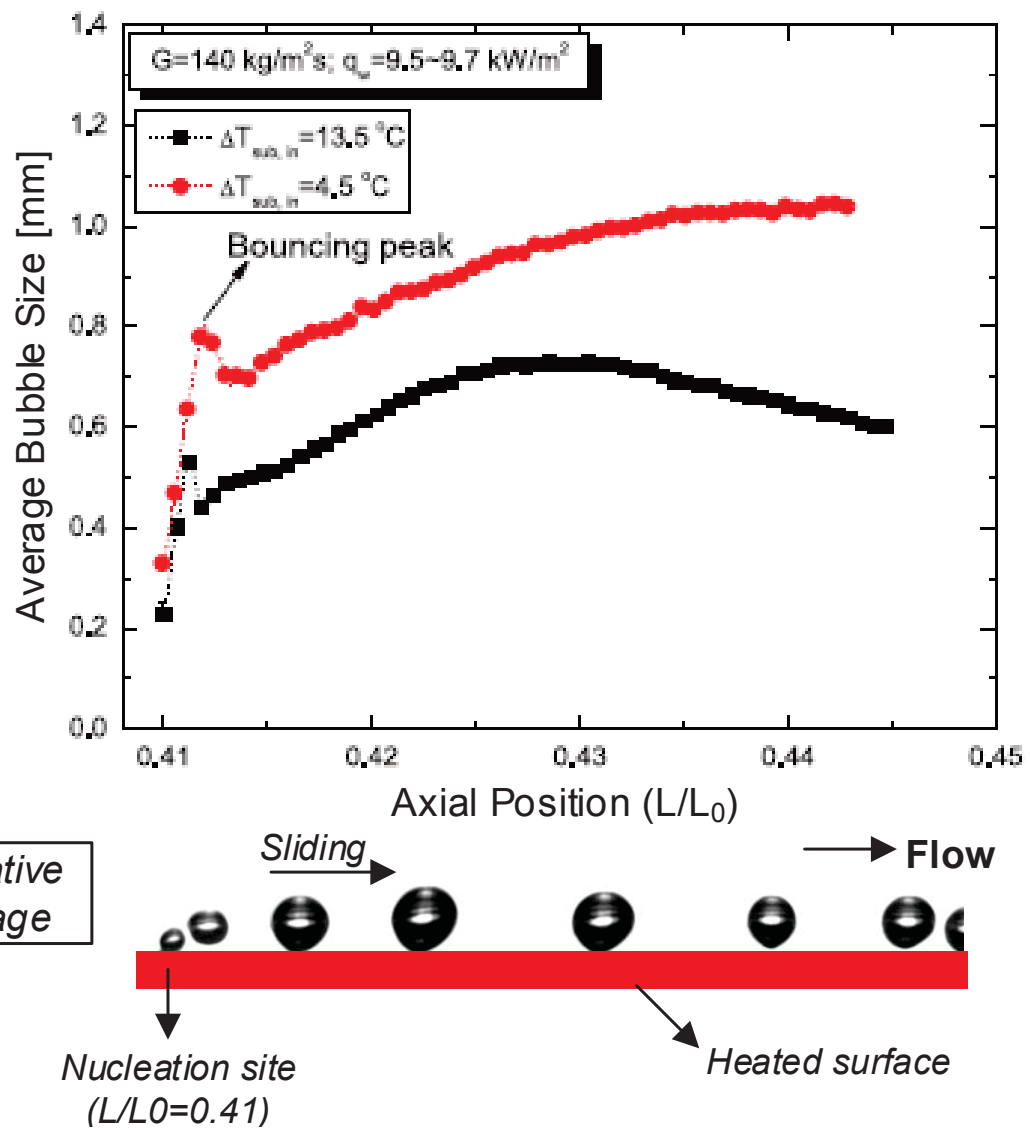

Figure 2. A typical growth behavior of sliding bubble after departure from a single nucleation site in TAMU subcooled flow boiling experiment 
Table 1 . Test boundary conditions and measured bubble parameters

\begin{tabular}{ccccccc}
\hline $\begin{array}{c}\text { Exp. } \\
\text { No. }\end{array}$ & $\begin{array}{c}G \\
\left(\mathrm{~kg} / \mathrm{m}^{2} \mathrm{~s}\right)\end{array}$ & $\begin{array}{c}q_{w} \\
\left(\mathrm{~kW} / \mathrm{m}^{2}\right)\end{array}$ & $\begin{array}{c}\Delta T_{\text {sub,in }} \\
(\mathrm{K})\end{array}$ & $J a^{a}$ & $\begin{array}{c}f_{b, 0}{ }^{b} \\
{[\mathrm{~Hz}]}\end{array}$ & $\begin{array}{c}D_{d} \\
{[\mathrm{~mm}]}\end{array}$ \\
\hline 1 & 140 & 9.7 & 13.5 & 34.1 & 159 & 0.44 \\
2 & 140 & 11.6 & 13.6 & 42.8 & 163 & 0.47 \\
3 & 140 & 8.1 & 13.5 & 24.1 & 152 & 0.42 \\
4 & 280 & 11.9 & 13.5 & 19.8 & 133 & 0.31 \\
5 & 420 & 12.2 & 13.5 & 6.3 & 239 & 0.08 \\
6 & 420 & 20.4 & 13.5 & 30.6 & 148 & 0.21 \\
7 & 420 & 23.7 & 13.5 & 39.5 & 282 & 0.23 \\
8 & 420 & 17.1 & 13.5 & 20.6 & 139 & 0.19 \\
9 & 560 & 24.0 & 13.6 & 24.2 & 207 & 0.18 \\
10 & 700 & 24.2 & 13.5 & 14.6 & 331 & 0.12 \\
11 & 700 & 30.9 & 13.5 & 27.1 & 343 & 0.12 \\
12 & 700 & 35.1 & 13.5 & 34.9 & 523 & 0.10 \\
13 & 700 & 26.4 & 13.6 & 18.4 & 295 & 0.12 \\
14 & 140 & 9.5 & 4.50 & 49.1 & 135 & 0.69 \\
15 & 420 & 20.1 & 4.50 & 45.8 & 380 & 0.30 \\
16 & 700 & 30.5 & 4.50 & 42.6 & 769 & 0.16 \\
\hline
\end{tabular}

a Jacob number at the elevation of nucleation site (estimated based on the average wall temperature measured at $L / L_{0} \approx 0.41$ )

${ }^{b}$ Bubble release frequency from a single nucleation site

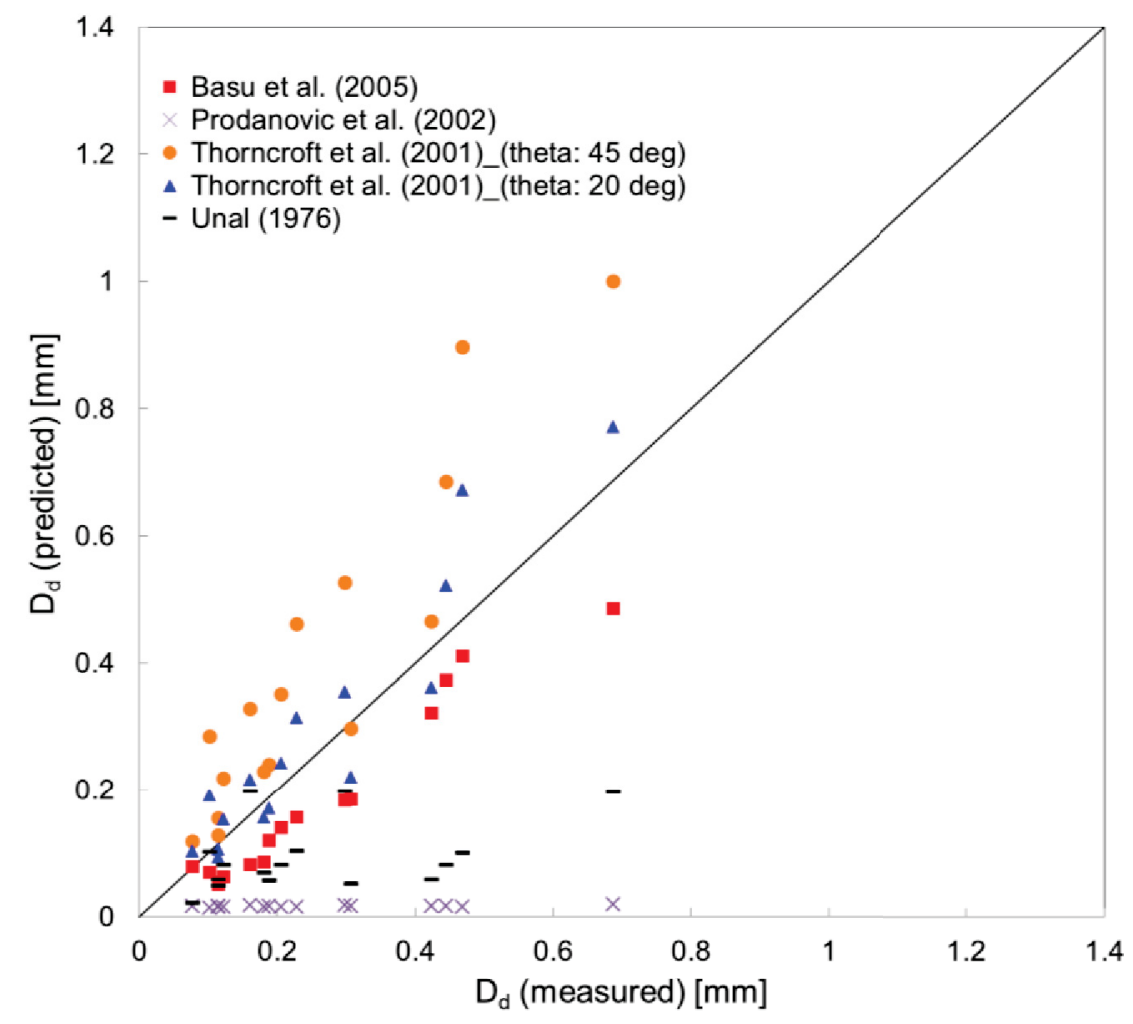

Figure 3. Comparison of measured bubble departure diameter with model predictions 


\section{REFERENCES}

1. Yoo, J., C.E. Estrada-Perez, and Y.A. Hassan, Experimental study on bubble dynamics and wall heat transfer arising from a single nucleation site at subcooled flow boiling conditions-Part 2: Data analysis on sliding bubble characteristics and associated wall heat transfer. International Journal of Multiphase Flow, 2016. 84: p. 292-314.

2. Yoo, J., Boiling Closure Model Validation/Development Effort with TAMU Experimental Data. 2016, CASL Milestone Report. INL/EXT-16-40015, Idaho National Laboratory, USA.

3. Yoo, J., C.E. Estrada-Perez, and Y.A. Hassan, Experimental study on bubble dynamics and wall heat transfer arising from a single nucleation site at subcooled flow boiling conditions-Part 1: Experimental methods and data quality verification. International Journal of Multiphase Flow, 2016. 84: p. 315-324.

4. Ünal, H., Maximum bubble diameter, maximum bubble-growth time and bubble-growth rate during the subcooled nucleate flow boiling of water up to $17.7 \mathrm{MN} / \mathrm{m} 2$. International Journal of Heat and Mass Transfer, 1976. 19(6): p. 643-649.

5. Basu, N., G.R. Warrier, and V.K. Dhir, Wall heat flux partitioning during subcooled flow boiling: Part 1-model development. Journal of heat Transfer, 2005. 127(2): p. 131-140.

6. Prodanovic, V., D. Fraser, and M. Salcudean, Bubble behavior in subcooled flow boiling of water at low pressures and low flow rates. International Journal of Multiphase Flow, 2002. 28(1): p. 1-19.

7. Thorncroft, G. and J.F. Klausner, Bubble forces and detachment models. Multiphase Science and Technology, 2001. 13(3\&4). 